\title{
Combined Advanced Finishing and UV-Laser Conditioning for Producing UV Damage Resistant Fused Silica Optics
}

Joseph A. Menapace, Bernie Penetrante,Don Golini, Al Slomba, Phil E. Miller, Tom Parham, Mike Nichols and John Peterson

This article was submitted to Laser-Induced Damage in Optical Materials, Nov.1-2, 2001 Boulder, CO.

November 1-2, 2001 


\section{DISCLAIMER}

This document was prepared as an account of work sponsored by an agency of the United States Government. Neither the United States Government nor the University of California nor any of their employees, makes any warranty, express or implied, or assumes any legal liability or responsibility for the accuracy, completeness, or usefulness of any information, apparatus, product, or process disclosed, or represents that its use would not infringe privately owned rights. Reference herein to any specific commercial product, process, or service by trade name, trademark, manufacturer, or otherwise, does not necessarily constitute or imply its endorsement, recommendation, or favoring by the United States Government or the University of California. The views and opinions of authors expressed herein do not necessarily state or reflect those of the United States Government or the University of California, and shall not be used for advertising or product endorsement purposes.

This is a preprint of a paper intended for publication in a journal or proceedings. Since changes may be made before publication, this preprint is made available with the understanding that it will not be cited or reproduced without the permission of the author.

This report has been reproduced directly from the best available copy.

Available to DOE and DOE contractors from the Office of Scientific and Technical Information

P.O. Box 62, Oak Ridge, TN 37831

Prices available from (423) 576-8401 http:/ /apollo.osti.gov/bridge/

Available to the public from the National Technical Information Service

U.S. Department of Commerce 5285 Port Royal Rd., Springfield, VA 22161

http://www.ntis.gov/

\section{OR}

Lawrence Livermore National Laboratory

Technical Information Department's Digital Library

http://www.llnl.gov/tid/Library.html 


\title{
Combined Advanced Finishing and UV-Laser Conditioning for Producing UV-Damage-Resistant Fused Silica Optics
}

\author{
Joseph A. Menapace ${ }^{a}$, Bernie Penetrante ${ }^{a}$, Don Golini ${ }^{b}$, Al Slomba ${ }^{c}$, \\ Phil E. Miller ${ }^{\mathrm{a}}$, Tom Parham ${ }^{\mathrm{a}}$, Mike Nichols ${ }^{\mathrm{a}}$, and John Peterson ${ }^{\mathrm{a}}$ \\ ${ }^{a}$ Lawrence Livermore National Laboratory, \\ 7000 East Avenue Livermore CA, 94550-9234 \\ ${ }^{\mathrm{b}}$ QED Technologies, LLC, 1040 University Avenue, Rochester NY 14607 \\ ${ }^{\mathrm{c}}$ Zygo Corporation, P.O. Box 448, Middlefield CT 06455-0448
}

\begin{abstract}
Laser induced damage initiation on fused silica optics can limit the lifetime of the components when used in high power UV laser environments. Foe example in inertial confinement fusion research applications, the optics can be exposed to temporal laser pulses of about 3-nsec with average fluences of $8 \mathrm{~J} / \mathrm{cm}^{2}$ and peak fluences between 12 and $15 \mathrm{~J} / \mathrm{cm}^{2}$.

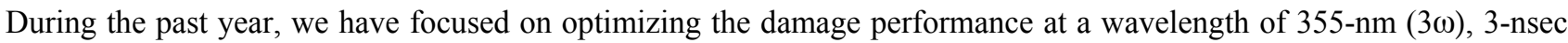
pulse length, for optics in this category by examining a variety of finishing technologies with a challenge to improve the laser damage initiation density by at least two orders of magnitude. In this paper, we describe recent advances in improving the $3 \omega$ damage initiation performance of laboratory-scale zirconium oxide and cerium oxide conventionally finished fused silica optics via application of processes incorporating magnetorheological finishing (MRF), wet chemical etching, and UV laser conditioning. Details of the advanced finishing procedures are described and comparisons are made between the procedures based upon large area $3 \omega$ damage performance, polishing layer contamination, and optical subsurface damage.
\end{abstract}

Keywords: magnetic fluid, polishing abrasives, magnetorheological finishing, subsurface damage, etching, UV laser conditioning, damage threshold, surface modification, polishing layer.

\section{INTRODUCTION}

Methods for reducing laser damage initiation sites that lead to catastrophic failure of fused silica optics are of critical importance to the laser-driven Inertial Confinement Fusion research (ICF) community. They are also of importance to the multi-billion dollar semiconductor capital equipment market. In lithography equipment used for manufacturing of silicon integrated circuits, ultraviolet light in the range of 340-360 nm is typically used. There are many commercial lasers that use light wavelengths at $360 \mathrm{~nm}$ or less. The ability to substantially improve the resistance to optical deterioration of laser components in such devices is important, since the chief limiting issue for laser materials is their laser damage performance. Unfortunately, success in using conventional polishing methods has been limited in reducing the initiation of damage sites when fused silica optics are exposed to high-power lasers at these wavelengths.

The sustained performance of high peak power lasers, such as those used for inertial ICF research, is limited by the damage to optical components ${ }^{1,2}$ that comprise the optical chain used to deliver the laser beam to the fusion capsule. The damage initiates in small (tens of micrometers) sites whose particular size is dependent upon the peak fluence of the laser. The size of the damage grows exponentially with the number of shots and can create excessive scatter and beam modulation $^{3}$. Replacing the damaged optics is an option for sustained performance of the laser system, but such an option is expensive. Methods of stopping damage growth have been recently developed, but their implementation requires a method of reducing the number of sites.

The largest and most powerful lasers designed for ICF research are flashlamp pumped neodymium-glass operate at a wavelength of $1053 \mathrm{~nm}$ which is then converted to a third harmonic $(3 \omega)$ at $351 \mathrm{~nm}^{4,5}$. In the final optics stage of an ICF

*Correspondence: Email: menapace1@1lnl.gov; Telephone: 925-423-0829; Fax: 925-422-5718 
laser, the infrared beams are converted to ultraviolet beams, and then focused onto the target. The final optics will be irradiated by a distribution of fluences, peaking at about $15 \mathrm{~J} / \mathrm{cm}^{2}$ for a $3-\mathrm{nsec}$ pulse at a wavelength of $351 \mathrm{~nm}$. Optical components, particularly made of fused silica, are essential for shaping the laser beams and delivering these beams to the target. These optics suffer from weakened areas that are prone to damage at the laser fluences expected or planned in the aforementioned laser systems. Damage can occur at the fundamental laser wavelength of $1053 \mathrm{~nm}$ and, especially, at the tripled wavelength of $351 \mathrm{~nm}$. There are two options that would enable continued use of the optics. One option is to mitigate the growth of the damage sites before they can create excessive scatter and beam modulation ${ }^{1,6-8}$. The other option is to drastically reduce the number of initiation sites present on the optics following optical finishing 9 .

Damage initiation on fused silica optics in high fluence UV laser environments can arise from various manufacturing flaws and handling processes used during optic fabrication. Improper handling and cleanliness of the optics can cause damage initiation by introducing contaminants onto the optical surfaces. Such contaminants can absorb energy and initiate damage upon laser beam exposure. Similarly, the conventional polishing process itself can lead to the formation of damage sites ${ }^{10-13}$. Such damage sites result from both surface and subsurface mechanical damage that is inherent to the high normal loads associated with conventional lap polishing. In addition to the mechanical damage itself, such surface and subsurface cracks can serve as sites that can trap optically absorbing species, such as iron, ceria, and other contaminants, which are typically present in the polishing process. While improvement in damage initiation density can be realized by utilizing zirconia-based polishing slurries ${ }^{14}$, conventional lap polishing inevitably results in both surface and subsurface mechanical damage due to the high normal loads present from the weight of the optic on the lap bed. Because of this, the subsurface damage layer persists regardless of how careful one is in controlling the process. Similar effects are observed with other types of conventional finishing such as small tool polishing.

Magnetorheological finishing ${ }^{15-21}$ (MRF) has been recently described as an advanced polishing technique that can finish optics without propagating the subsurface damage layer. The technique can also remove preexisting subsurface damage

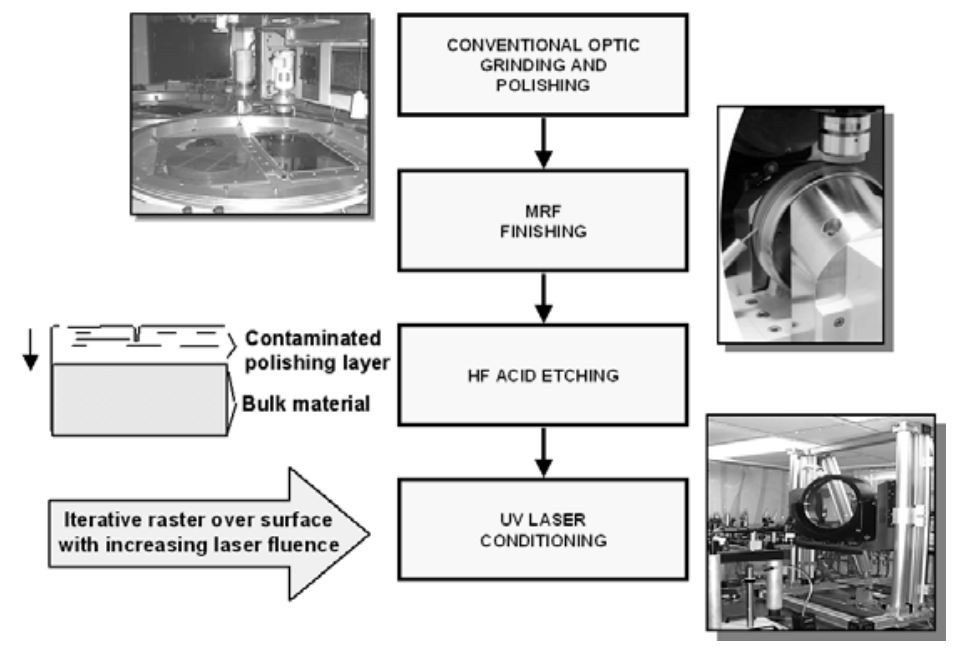

Figure 1: Combined advanced finishing recipe to improve UV damage resistance of fused silica optics. under the correct conditions. The removal of subsurface damage using MRF can be attributed to the small normal stress applied to the glass surface compared to large shear stress which is created by the interaction of the tool's magnetic field and the MR fluid through the converging gap between the optic and tool's pole faces. The shear stress applied to the optic results in high rates of material removal with little medial crack formation.

This paper compares the results of $3 \omega$ damage testing on conventionally polished optics and optics polished using MRF. Additional postprocessing procedures involving hydrofluoric acid etching $^{22}$ and $3 \omega$ laser conditioning ${ }^{9}$ are also discussed which, when combined with conventional polishing and MRF polishing, result in improved $3 \omega$ damage resistance when compared to the use of any of the techniques when used alone. This combined advanced finishing process provides a means of fabricating UV damage resistant optical components with minimal changes in the manufacturing process as shown in Figure 1.

\section{EXPERIMENTAL}

The experimental matrix shown in Table 1 is designed to explore the effects of MRF, HF etching, and UV laser conditioning on conventionally finished optics provided by different vendors. Both large aperture and subscale optics are considered in the experiments to illustrate any differences in performance due to vendor specific processes. The samples polished by Zygo consist of $15.2 \mathrm{~cm}$-diameter by $1.0-\mathrm{cm}$ thick fused silica optics (Corning 7980). These specimens were prepared by conventionally polishing both sides of the optics using best-known continuous pitch polishing 
techniques and zirconia (ZrOx) slurry. A subset of the optics was also subjected to MRF final polishing using standard ceria $(\mathrm{CeOx})$ slurry contained in an iron based MR fluid media. For these specimens, $1 \mu \mathrm{m}$ of material was removed

Table 1: Experimental matrix used to compare various finishing and post-processing techniques on the vendor supplied optics. $X$ identifies the processes that are explored via large area damage testing.

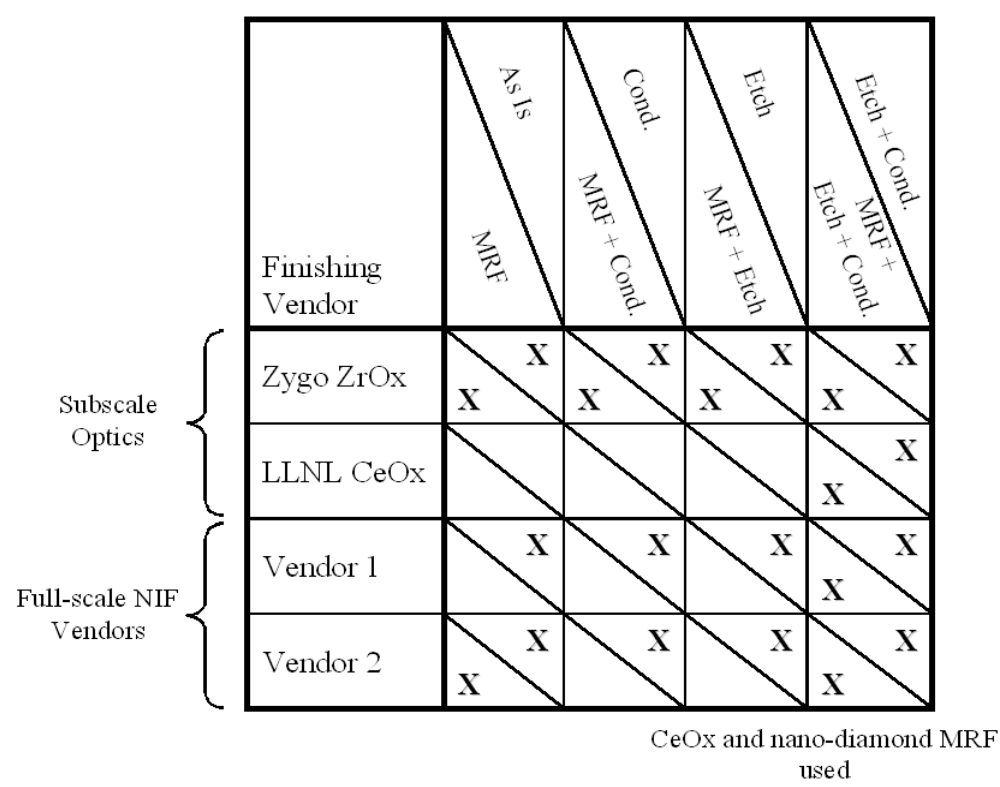
using MRF. The "Vendor 1", Table 1, optics consist of subsections cut from a $43-\mathrm{cm}$ X $43-$ $\mathrm{cm}$ X 2.5-cm large aperture optic (Corning 7980 fused silica) originally prepared in 2000 using a proprietary best-known process that optimizes $3 \omega$ damage performance. These optics represent our reference for the present studies since they are the best-performing conventionally finished large optics tested at LLNL. The subsections used in the experiments were square measuring $14.3-\mathrm{cm} X 14.3-\mathrm{cm} \times 2.5-\mathrm{cm}$ thick. The "Vendor 2" optics consist of subsections cut from a 43-cm X 43-cm X 1.0-cm large aperture optic originally prepared in 1999 during the early portion of our large aperture optic finishing development efforts. During the polishing of these optics, little attention was paid to the type of polishing slurry used and the extent of subsurface damage encountered during the fabrication process. The subsections were square measuring $14.3-\mathrm{cm} \mathrm{X} \mathrm{14.3-cm} \mathrm{X}$ $1.0-\mathrm{cm}$ thick. The LLNL-polished specimens consist of subsections cut from a large aperture optic of the same vintage as that provided by "Vendor 2". The subsections were subjected to

additional finishing at LLNL using continuous pitch polishing techniques and CeOx slurry with which $25 \mu \mathrm{m}$ of fused silica was removed from each of the optical surfaces. Selected optics from these latter types were subjected to MRF final polishing at QED where a uniform layer of fused silica was removed from each of the optic surfaces using CeOx or nano-diamond MR fluid media.

In all experiments, the optics were cleaned using our best-known cleaning procedures ${ }^{23}$ prior to etching and optimized $3 \omega$ laser conditioning/damage testing. This cleaning procedure included a standard buffing with colloidal alumina as one of the cleaning steps. The etched specimens were prepared at LLNL by immersing the cleaned optics in an aqueous solution of 20:1 low-particulate-grade buffered-oxide etch composed of $38 \%(\mathrm{w} / \mathrm{w})$ ammonium fluoride and $2.45 \%$ (w/w) HF at $23 \mathrm{C}$. After a 57 minutes immersion time, $2 \mu \mathrm{m}$ of fused silica was removed from both of the optical surfaces of the Zygo-supplied samples. The other optic types were immersed for 28 minutes to remove $1 \mu \mathrm{m}$ of material from the optical surfaces. The optics were subsequently washed thoroughly using distilled de-ionized water, dried, and cleaned by LLNL personnel using the fused silica optics cleaning procedures described above.

Large area damage testing ${ }^{24}$ was conducted using a frequency-tripled Spectra-Physics Nd:YAG laser operating at 355$\mathrm{nm}$ with a 7.5-nsec temporal system pulse width and a spot size of $\sim 1 \mathrm{~mm}$. Peak laser fluence was determined using the peak fluence measured for a Gaussian-shaped beam spot scaled from the system temporal pulse width to an equivalent 3nsec wide pulse by $\tau^{1 / 2}$ scaling, where $\tau$ represents the ratio of the pulse lengths. Area scans were conducted with raster step sizes corresponding to the measured Gaussian width at $50 \%$ of the peak intensity value. The peak probe fluence was held within $+/-5 \%$ of target via computer control of the laser system's energy attenuator. Damage detection and quantification was accomplished by side lighting the optic with white light and imaging the area of optic being damage tested onto a scanning linear CCD mega-pixel array ${ }^{24}$. This diagnostic enabled a digital micrograph to be generated of the area under test that highlighted defects within the bulk and on the optic surface with a resolution of $80-\mu \mathrm{m} / \mathrm{pixel}$ and $10-\mu \mathrm{m}$ sensitivity. The digital micrograph was subsequently analyzed and defects identified via threshold image processing and counting techniques. The area scaling approach described by Schwartz, et al. ${ }^{24}$, was not used due to the difficulty in selecting Weibull coefficients when no damage can be observed in the tested area. All values are therefore reported as raw, uncorrected damage densities. 
For the optics that were not subjected to laser conditioning, large area damage testing was conducted by raster scanning over the test areas while holding the laser fluence constant. For the laser conditioned optics, the specimens were subjected to 3 large area laser scans at a pulse width of $7.5 \mathrm{nsec}$ and peak fluences of 4,6 , and $8 \mathrm{~J} / \mathrm{cm}^{2}$, each before being probed at laser fluences starting at $10 \mathrm{~J} / \mathrm{cm}^{2}$. As in the unconditioned experiments, these large area laser raster scans were conducted over the test areas while holding the laser fluence constant.

\section{RESULTS AND DISCUSSION}

\subsection{Zygo ZrOx Conventionally Finished and MRF Finished Fused Silica Optics}

The finished optics supplied by Zygo demonstrate the feasibility of using MRF in fabricating $3 \omega$ damage-resistant optics. These experiments provide a direct comparison between the damage densities of the two optics that were prepared identically by lap polishing using ZrOx slurry, one of which was subjected to further finishing by MRF and one of which was not. The experiments also provide information central to the development of the combined MRF, wet etching, and $3 \omega$ post processing procedure used to yield superior performance optics. The results of large area damage testing conducted on each of the specimens are listed in Tables 2 and 3 and plotted in Figures 2 and 3.

Table 2: Damage density observed on $15.2-\mathrm{cm}$-diameter by $1.0-\mathrm{cm}$-thick fused silica samples polished by $\mathrm{Zygo}$ using $\mathrm{ZrOx}$ conventional polishing. Reported damage density is in sites/cm ${ }^{2}$ after illumination by 1 shot/site at $355 \mathrm{~nm}$ with no correction for beam shape. Fluences are scaled to equivalent values at 3-nsec.

\begin{tabular}{|c|c|c|c|c|}
\hline $\begin{array}{c}\text { Fluence } \\
\left(\mathbf{J} / \mathbf{c m}^{\mathbf{2}}\right)\end{array}$ & $\begin{array}{c}\text { Zygo ZrOx } \\
\text { As Is }\end{array}$ & $\begin{array}{c}\text { Zygo Conditioned } \\
\mathbf{Z r O x}\end{array}$ & $\begin{array}{c}\text { Zygo Etched } \\
\text { ZrOx }\end{array}$ & $\begin{array}{c}\text { Zygo Etched - } \\
\text { Conditioned ZrOx }\end{array}$ \\
\hline $\mathbf{4}$ & 0.00 & 0.00 & 0.00 & 0.00 \\
\hline $\mathbf{6}$ & 0.00 & 0.00 & 0.00 & 0.00 \\
\hline $\mathbf{8}$ & 0.00 & 0.00 & 0.00 & 0.00 \\
\hline $\mathbf{1 0}$ & 0.32 & 0.03 & 0.00 & 0.00 \\
\hline $\mathbf{1 2}$ & 1.00 & 0.25 & 0.81 & 0.02 \\
\hline $\mathbf{1 4}$ & Not Tested & 1.00 & 1.25 & 0.11 \\
\hline
\end{tabular}

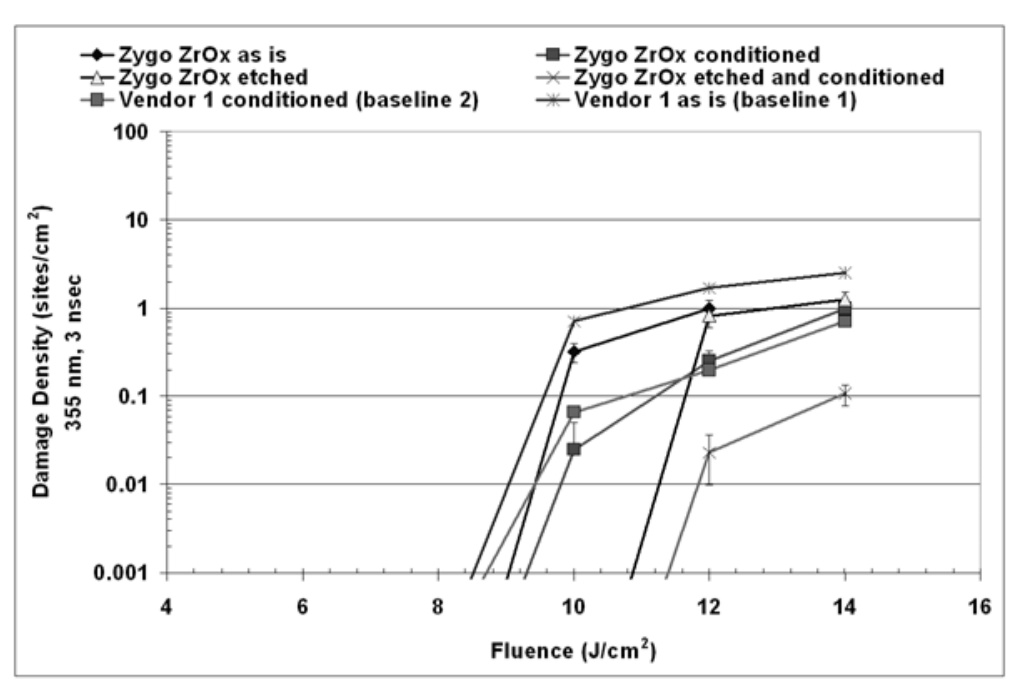

Figure 2: Damage density observed at $355 \mathrm{~nm}, 3 \mathrm{nsec}$, on $15.2 \mathrm{~cm}$ diameter by $1.0 \mathrm{~cm}$ thick fused silica samples polished by Zygo using ZrOx conventional polishing.
Large area damage testing on the Zygo ZrOx conventionally finished parts yields damage densities comparable to those observed on optics that are conventionally finished using the best known methods for $3 \omega$ fused silica fabrication, Table 2 and Figure 2. The comparisons are based upon damage densities taken from measurements made in March 2001 on a $43-\mathrm{cm} \mathrm{X} \mathrm{43-cm} \mathrm{X} \mathrm{2.5-cm} \mathrm{large}$ aperture flat optic supplied by Vendor 1 that represented the best $3 \omega$ optic fabrication procedure known at that time. The unetched and unconditioned Zygo $\mathrm{ZrOx}$ finished part (Zygo ZrOx as is) exhibits damage performance about 1.5-2 times better than the unetched and unconditioned Vendor 1 supplied optic (baseline 1). This supports earlier experience that the using $\mathrm{ZrOx}$ slurry during the entire conventional finishing process reduces the deleterious effects arising from light absorbing species, such as $\mathrm{CeOx}$ slurry, which can be introduced into the surface polishing and subsurface damage layers. These layers typically contain an admixture of polishing slurry and other contaminants that cause damage when irradiated at high laser fluence. With $3 \omega$ laser conditioning (Zygo ZrOx conditioned), a factor of 3-10 improvement in performance is observed over that of the unetched $\mathrm{ZrOx}$ polished optic. 
This places its damage performance between typical and the best damage performance observed on large aperture flat optics (Vendor 1 conditioned baseline 2). The improvement is most pronounced at lower laser fluences. This is similar to the factor of 3-8 improvements in damage density that results from conventional CeOx polished optics that are etched. Etching $2 \mu \mathrm{m}$ from the surfaces of the ZrOx finished optic (Zygo ZrOx etched) improves damage performance to a level equivalent to that observed on parts that undergo $3 \omega$ laser conditioning. Laser conditioning at $3 \omega$ of the etched ZrOx part (Zygo ZrOx etched and conditioned) yields a performance improvement beyond the best damage performance observed for conditioned high quality optics (Vendor 1 conditioned, baseline 2) by about a factor of 10. The improvements achieved by the combination of etching and $3 \omega$ laser conditioning processes on the $\mathrm{ZrOx}$ optics suggest that particulate or thin film contamination is present in the polishing and subsurface damage layers which impacts damage performance. Etching is successful in removing or minimizing this contamination and its effects on laser damage performance and $3 \omega$ conditioning provides for further improvement by removing what the etching process leaves behind.

Large area damage testing on the Zygo MRF finished parts, Table 3 and Figure 3, yields mixed results ranging from among the worst to the best-performing optic depending upon the post-MRF polishing procedures used.

Table 3: Damage density observed on 15.2-cm-diameter by 1.0-cm-thick fused silica samples polished by Zygo using ZrOx conventional polishing techniques and final polished using MRF to remove $1 \mu \mathrm{m}$ of material. Reported damage density is in sites $/ \mathrm{cm}^{2}$ after illumination by 1 shot/site at $355 \mathrm{~nm}$ with no correction for beam shape. Fluences are scaled to equivalent values at 3-nsec.

\begin{tabular}{|c|c|c|c|c|}
\hline $\begin{array}{c}\text { Fluence } \\
\left(\mathbf{J} / \mathbf{c m}^{\mathbf{2}}\right)\end{array}$ & $\begin{array}{c}\text { Zygo 1 } \boldsymbol{\mu m} \text { CeOx } \\
\text { MRF As Is }\end{array}$ & $\begin{array}{c}\text { Zygo Conditioned } \\
\mathbf{1} \boldsymbol{\mu} \mathbf{m} \text { CeOx MRF }\end{array}$ & $\begin{array}{c}\text { Zygo Etched 1 } \boldsymbol{\mu m} \\
\text { CeOx MRF }\end{array}$ & $\begin{array}{c}\text { Zygo Etched - Conditioned } \\
\mathbf{1} \boldsymbol{\mu m} \text { CeOx MRF }\end{array}$ \\
\hline $\mathbf{4}$ & 0.00 & 0.00 & 0.00 & 0.00 \\
\hline $\mathbf{6}$ & 0.00 & 0.00 & 0.00 & 0.00 \\
\hline $\mathbf{8}$ & 0.00 & 0.83 & 0.00 & 0.00 \\
\hline $\mathbf{1 0}$ & 0.56 & 6.70 & 0.00 & 0.00 \\
\hline $\mathbf{1 2}$ & 11.40 & Gray Haze & 0.06 & 0.01 \\
\hline $\mathbf{1 4}$ & Gray haze & Not Tested & 1.06 & 0.02 \\
\hline
\end{tabular}

Significant damage densities are observed on the unetched Zygo CeOx MRF finished optics when tested under both unconditioned and $3 \omega$ laser conditioned procedures. The unetched and unconditioned MRF optic (Zygo $1 \mu \mathrm{m}$ $\mathrm{CeOx}$ MRF as is) possesses unacceptable damage density of $0.56 \mathrm{sites} / \mathrm{cm}^{2}$ at $10 \mathrm{~J} / \mathrm{cm}^{2}$ and $11.40 \mathrm{sites} / \mathrm{cm}^{2}$ at $12 \mathrm{~J} / \mathrm{cm}^{2}$. Damage is even more severe during and after $3 \omega$ laser conditioning with the conditioned MRF part (Zygo conditioned $1 \mu \mathrm{m} \quad \mathrm{CeOx}$ MRF) displaying damage densities near 0.83 sites $/ \mathrm{cm}^{2}$ at $8 \mathrm{~J} / \mathrm{cm}^{2}$ and 6.70 sites $/ \mathrm{cm}^{2}$ at 10 $\mathrm{J} / \mathrm{cm}^{2} .3 \omega$ laser conditioning in this instance is counterproductive. Such results are unexpected based upon previous experience with improvements gained by laser conditioning on conventionally finished optics. As such, damage testing was not conducted at higher fluences due to the risk of catastrophic failure. The poor performance of

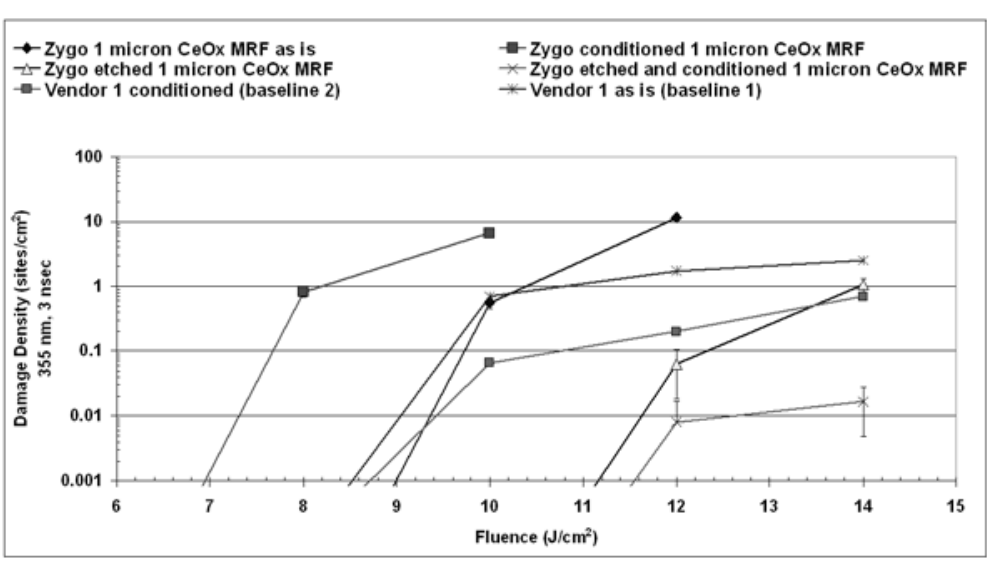

Figure 3: Damage density observed at $355 \mathrm{~nm}, 3 \mathrm{nsec}$, on $15.2 \mathrm{~cm}$ diameter by $1.0 \mathrm{~cm}$ thick fused silica samples polished by Zygo using ZrOx conventional polishing techniques and final polished using MRF to remove $1 \mu \mathrm{m}$ of material. the unetched MRF optics can most likely be attributed to optically absorbing iron and CeOx media used by the MRF tool during finishing. These materials have a high probability of combining with, or being present in, the optic surfaces as thin films or particulate inclusions in the surface polishing and subsurface damage layers. Etching $2 \mu \mathrm{m}$ from the surfaces of the MRF polished specimen yields a significant improvement in damage performance. Testing of the etched MRF finished optics (Zygo etched $1 \mu \mathrm{m} \mathrm{CeOx} \mathrm{MRF)} \mathrm{results} \mathrm{in} \mathrm{damage} \mathrm{performance} \mathrm{equivalent} \mathrm{to} \mathrm{that} \mathrm{observed} \mathrm{for} \mathrm{the}$ 
etched and unconditioned $\mathrm{ZrOx}$ finished parts, unetched and $3 \omega$ laser conditioned $\mathrm{ZrOx}$ finished parts, and conditioned high quality optics (Vendor 1 conditioned, baseline 2). Again, the improvement brought about by etching is more pronounced at lower laser fluences. Combining the etching process with $3 \omega$ laser conditioning (Zygo etched and conditioned $1 \mu \mathrm{m} \mathrm{CeOx} \mathrm{MRF)} \mathrm{yields} \mathrm{damage} \mathrm{performance} \mathrm{superior} \mathrm{to} \mathrm{any} \mathrm{previously} \mathrm{observed} \mathrm{on} \mathrm{high} \mathrm{quality}$ conventionally finished large aperture optics (Vendor 1 baselines 1 and 2). The damage density observed using this combined procedure is 0.02 sites $/ \mathrm{cm}^{2}$ at $14 \mathrm{~J} / \mathrm{cm}^{2}$ which is about a factor of $50-150$ times lower than the densities observed on Vendor 1 supplied optics. More important, damage is not observed at fluences less than $12 \mathrm{~J} / \mathrm{cm}^{2}$, and only a single damage site observed at $12 \mathrm{~J} / \mathrm{cm}^{2}$ over a $122-\mathrm{cm}^{2}$ analysis area. This behavior has not been previously observed on any conventionally finished optic tested at LLNL. The damage density at $14 \mathrm{~J} / \mathrm{cm}^{2}$ is also impressive with only 2 cumulative damage sites observed over the same analysis area. The damage test results suggest that etching the surface of the optics removes MRF-induced contamination (iron and/or CeOx) present in a thin polishing layer. The removal of this layer by etching and $3 \omega$ laser conditioning leaves a new exposed surface free from contamination and few to no pits and cracks that could interact with the laser probe to induce damage.

Chemical analysis of the etch solutions used to process the Zygo ZrOx conventionally polished and MRF optics gives an indication of the polishing layer composition that is removed from the optical surfaces by etching. For the ZrOx polished parts, $8.15 \mathrm{ppmw}$ of zirconium, $0.46 \mathrm{ppmw}$ of cerium, and $1.62 \mathrm{ppmw}$ of iron are measured with respect to the fused silica removed in the etch solutions after removal of $2 \mu \mathrm{m}$ of $\mathrm{SiO}_{2}$ from the optical surfaces via etching. These assays provide evidence indicating that conventional polishing leaves a polishing layer and potentially a subsurface damage layer at or near the optical surfaces which is composed of an admixture of materials contained in the polishing slurry and from other contaminants from other polishing and finishing steps. Removal of these contaminants using wet acid etching explains the improvement in damage performance observed as both of the contaminants absorb strongly in the ultraviolet. For the MRF-finished optics, $5.67 \mathrm{ppmw}$ of cerium and $5.36 \mathrm{ppmw}$ of iron are measured with respect to the fused silica removed in the solutions after removal of $2 \mu \mathrm{m}$ of $\mathrm{SiO}_{2}$ from the optical surfaces via etching. The final MRF polish appears to successfully remove the zirconium in the optical surfaces left behind by conventional polishing but generates a new polishing layer containing MR fluid components. The amounts of iron and cerium measured in this instance shows that contamination by absorbing species at ppmw levels are sufficient to deteriorate the optic's damage

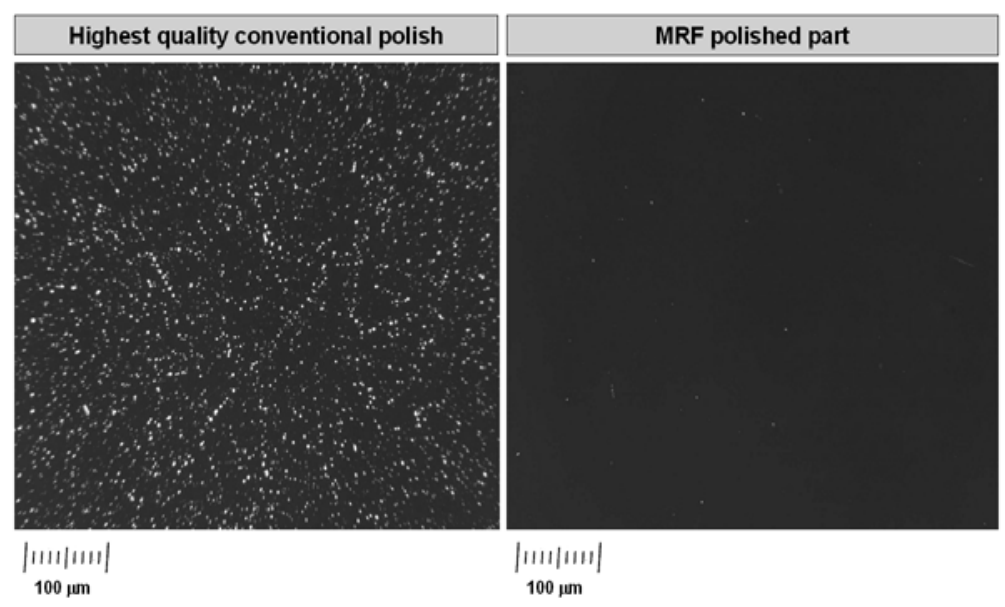

Figure 4: After etching, comparison of dark-field microscopy on highest quality, conventionally polished parts and MRF polished parts illustrate the dramatic decrease in scatter sites and "chatter marks" normally associated with subsurface damage from conventional finishing.

on the optic surfaces and can be easily removed with etching. Dark-field microscopy of the etched parts shows that MRF finishing results in a dramatic reduction in subsurface damage when compared to that present on conventionally polished parts, Figure 4. The large number of scatter sites and "chatter" on the conventionally lapped optical surfaces suggests that the subsurface damage layer is significant in spite of care taken to manage the damage during polishing. It also suggests that the large number of sites lead to a high probability for retention of absorbing species that can initiate 
damage when irradiated at high fluence. In contrast, the etched MRF polished optical surfaces show a near absence of subsurface damage that explains the large improvement observed in damage performance when compared to the best performing conventionally polished optics.

\subsection{MRF Final Finishing and 3 $\omega$ Post Processing of Vendor 1 Conventionally Finished Fused Silica Optics}

The experiments involving the application of various combinations of MRF final polishing, wet etching, and $3 \omega$ post processing techniques to subsections cut from the fused silica flat provided by Vendor 1 are intended to show that improvements in damage performance can be made beyond that observed for the best performing large aperture conventional finishing process. As in the case for the Zygo-prepared optics, these experiments allow for direct comparison of the combined $3 \omega$ finishing process on optics that are fabricated using the same process steps. The experiments are also meant to test if different MR fluid media and MRF removal amounts can impact the optical damage performance. In these instances, MR fluids containing nano-diamond and $\mathrm{CeOx}$ polishing media are examined. For MRF final finishing using $\mathrm{CeOx}$ MR fluid, two different removal amounts are explored which include 0.25 and $1 \mu \mathrm{m}$ material removal from both optical surfaces.

The results of large area damage testing conducted on each of the specimens are listed in Table 3 and plotted in Figure 5. Etching $1 \mu \mathrm{m}$ from the surfaces of the Vendor 1 supplied optic results in about a factor of 4 improvement in the damage

Table 3: Damage density observed on $14.3-\mathrm{cm} \times 14.3-\mathrm{cm} \times 2.5-\mathrm{cm}$ fused silica optic cut from full size NIF flat optic polished by Vendor 1 . Reported damage density is in sites/cm $\mathrm{cm}^{2}$ after illumination by 1 shot/site at $355 \mathrm{~nm}$ with no correction for beam shape. Fluences are scaled to equivalent values at 3-nsec.

\begin{tabular}{|c|c|c|c|c|c|c|}
\hline $\begin{array}{c}\text { Fluence } \\
\left(\mathbf{J} / \mathbf{c m}^{2}\right)\end{array}$ & $\begin{array}{c}\text { Vendor } \\
\mathbf{1} \text { Etched }\end{array}$ & $\begin{array}{c}\text { Vendor 1 } \\
\text { Etched - } \\
\text { Conditioned }\end{array}$ & $\begin{array}{c}\text { Vendor 1 } \\
\text { Conditioned 1 } \\
\boldsymbol{\mu m} \text { nano- } \\
\text { diamond MRF }\end{array}$ & $\begin{array}{c}\text { Vendor 1 Etched - } \\
\text { Conditioned 1 } \boldsymbol{\mu m} \\
\text { nano-diamond MRF }\end{array}$ & $\begin{array}{c}\text { Vendor 1 Etched } \\
\text { - Conditioned } \\
\mathbf{0 . 2 5} \boldsymbol{\mu m} \text { CeOx } \\
\text { MRF }\end{array}$ & $\begin{array}{c}\text { Vendor 1 } \\
\text { Etched - } \\
\text { Conditioned 1 } \\
\mu \mathbf{m} \text { CeOx MRF }\end{array}$ \\
\hline $\mathbf{4}$ & 0.00 & 0.00 & 0.00 & 0.00 & 0.00 & 0.00 \\
\hline $\mathbf{6}$ & 0.00 & 0.00 & 0.00 & 0.00 & 0.00 & 0.00 \\
\hline $\mathbf{8}$ & 0.00 & 0.02 & 4.04 & 0.00 & 0.00 & 0.00 \\
\hline $\mathbf{1 0}$ & 0.17 & 0.04 & Gray Haze & 0.02 & 0.01 & 0.01 \\
\hline $\mathbf{1 2}$ & 0.43 & 0.07 & Not Tested & 0.07 & 0.06 & 0.02 \\
\hline $\mathbf{1 4}$ & 0.65 & 0.23 & Not Tested & 0.14 & 0.23 & 0.08 \\
\hline
\end{tabular}

performance over that observed for the unprocessed part (Vendor 1 as is baseline 1). Applying $3 \omega$ laser conditioning to the etched optic further improves the part performance by about a factor of 11, with the optic performing about a factor of 3 better that the Vendor 1 conditioned optic, baseline 2. The increase in damage resistance produced by etching and $3 \omega$ laser conditioning is consistent with the performance enhancement observed on the Zygo supplied parts and shows that $3 \omega$ post processing itself can be a valuable tool to minimize damage initiation under high fluence conditions.

Final polishing of the Vendor 1 optics using MRF with nano-diamond MR fluid to remove $1 \mu \mathrm{m}$ of $\mathrm{SiO}_{2}$ from the optical surfaces yields results similar to that observed for the Zygo-supplied specimens. Again, large area damage testing on the optics yields mixed results ranging from unacceptable for high fluence laser application to superior performance depending upon the post-MRF procedures used. For the unetched and laser conditioned nano-diamond polished MRF optic, significant damage densities are observed at low fluence, 4.04 sites $/ \mathrm{cm}^{2}$ at $8 \mathrm{~J} / \mathrm{cm}^{2}$ with the appearance of gray haze at $10 \mathrm{~J} / \mathrm{cm}^{2}$. Additional testing of the unetched optic and unconditioned optic was not pursued as it is expected to perform poorly based upon the results of the Zygo provided samples. Etching $1 \mu \mathrm{m}$ of $\mathrm{SiO}_{2}$ from the surfaces of the nano-diamond MRF polished samples and application of $3 \omega$ laser conditioning leads to an improvement in damage performance equivalent to simply etching and laser conditioning the Vendor 1 supplied optic. Larger damage sites are observed, however, for these optics when compared to the sites observed on conventionally polished and CeOx MRF polished parts. Even though the nano-diamond portion of the MR fluid is not expected to interact with the polishing layer on the optical surfaces as is the case for $\mathrm{CeOx}$ MR fluid media, the interaction occurring at the glass surface apparently leaves an admixture of iron and diamond in the polishing layer. This explains the unacceptable performance that is observed on the conditioned part and the damage resistance improvements realized after etching. Etching appears to be effective at removing most of the contamination present but seems to leave behind nano-diamond remnants that promote larger damage sites when interacting with the laser beam at high fluence. As the nano-diamonds used in the MR 
fluid are anthropogenic, it is possible that they contain contaminants that can contribute to damage observed in the fused silica parts even though one would conclude that the diamond itself does not contribute. Furthermore, it is possible that contaminants in the nano-diamonds are initiating damage to the diamonds that subsequently results in collateral damage to the glass.

MRF removal of $0.25 \mu \mathrm{m}$ of fused silica from the surfaces of the Vendor 1 optics using CeOx MR fluid followed by etching of $1 \mu \mathrm{m}$ from the optical surfaces and $3 \omega$ laser conditioning results in damage performance improvement equivalent to that observed on the $1 \mu \mathrm{m}$ nano-diamond MRF and $3 \omega$ post-processed specimens. In this case, the damage performance is about a factor of 3-4 times better than the best performing conventionally finished optic after undergoing

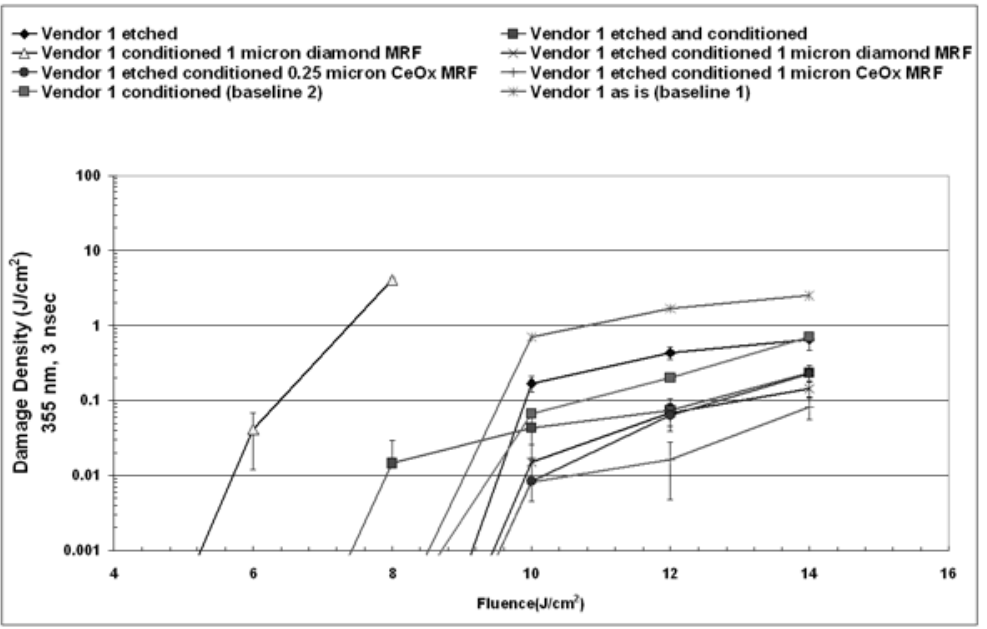

Figure 5: Damage density observed at $355 \mathrm{~nm}, 3 \mathrm{nsec}$, on $14.3-\mathrm{cm} x$ $14.3-\mathrm{cm} \times 2.5-\mathrm{cm}$ fused silica optic cut from full size NIF flat optic polished by Vendor 1.
$3 \omega$ laser conditioning, Vendor 1 Conditioned, Figure 4. MRF removal of $1 \mu \mathrm{m}$ of fused silica from the optical surfaces using $\mathrm{CeOx} \mathrm{MR}$ fluid and $3 \omega$ post-processing provides nearly a factor of 9-12 improvement. The improvement, however, is not as large as that observed on the Zygo provided MRF polished specimens, 0.08 sites $/ \mathrm{cm}^{2}$ versus 0.02 sites $/ \mathrm{cm}^{2}$. This observation could lead to the conclusion that the quality of the optic before MRF has some effect on its ultimate laser damage performance. It is highly likely that the ultimate damage performance of the optic depends upon the subsurface damage layer thickness and the contaminants residing therein and that the $\mathrm{MRF} / 3 \omega$ post-processing procedure may need to be optimized to ensure that sufficient material removal is accomplished to realize ultimate and reliable performance. Further experiments in this area are necessary in order to confirm the observation and form a sound conclusion.

\subsection{MRF Final Finishing and 3 $\omega$ Post Processing of Vendor 2 Conventionally Finished Fused Silica Optics}

Application of MRF final polishing and $3 \omega$ post processing techniques to subsections cut from the fused silica flat provided by Vendor 2 are meant to illustrate that improvements in damage performance can be made on optics that are unacceptable for high fluence ultraviolet laser applications. These represent optics for which little to no attention was paid to the type of polishing slurry used nor to the extent of subsurface damage encountered during the fabrication process. The results of large aperture damage testing on the subsections are presented in Table 4 and Figure 6.

The damage performance observed on the unetched and unconditioned part (Vendor 2 as is) identifies its usefulness as marginal with a damage density of about 0.2 sites $/ \mathrm{cm}^{2}$ at fluences in the range of $4-8 \mathrm{~J} / \mathrm{cm}^{2}$. At laser fluences above 10 $\mathrm{J} / \mathrm{cm}^{2}$, the damage density drastically increases and quickly becomes severe with a value of $314 \mathrm{sites} / \mathrm{cm}^{2}$ at $14 \mathrm{~J} / \mathrm{cm}^{2}$. Damage densities at these levels make the part unacceptable for use due to the risk of catastrophic failure from damage growth. The damage morphology is recognizable and typical for a part that has been conventionally finished using $\mathrm{CeOx}$ lap techniques. The optical surface appears "hazy" with a large number of pinpoint fractures indicating that the surface contains contaminated polishing and subsurface damage layers that are laden with contaminants. Etching $1 \mu \mathrm{m}$ from the surfaces or conducting laser conditioning improves the damage performance by about a factor of 100 , however, either treatment only improves the optic to a point equivalent to that observed on the Vendor 1 unetched and unconditioned part (Vendor 1 as is, baseline 1). Combined etching and $3 \omega$ laser conditioning improves the conventionally finished part by a factor of 300 with values in the vicinity of $0.2-1 \mathrm{sites} / \mathrm{cm}^{2}$ between $10 \mathrm{and} 14 \mathrm{~J} / \mathrm{cm}^{2}$. 
Table 4: Damage density observed on $14.3-\mathrm{cm} \times 14.3-\mathrm{cm} \times 1.0-\mathrm{cm}$ fused silica optic cut from full size NIF high aspect ratio optic polished by Vendor 2. Reported damage density is in sites/cm ${ }^{2}$ after illumination by 1 shot/site at $355 \mathrm{~nm}$ with no correction for beam shape. Fluences are scaled to equivalent values at 3-nsec.

\begin{tabular}{|c|c|c|c|c|c|c|}
\hline $\begin{array}{c}\text { Fluence } \\
\left(\mathbf{J} / \mathbf{c m}^{2}\right)\end{array}$ & $\begin{array}{c}\text { Vendor } \\
\mathbf{2} \text { As is }\end{array}$ & $\begin{array}{c}\text { Vendor 2 } \\
\text { Conditioned }\end{array}$ & $\begin{array}{c}\text { Vendor 2 } \\
\text { Etched }\end{array}$ & $\begin{array}{c}\text { Vendor 2 } \\
\text { Etched and } \\
\text { Conditioned }\end{array}$ & $\begin{array}{c}\text { Vendor 2 Etched } \\
\text { - Conditioned 1 } \\
\mu \mathbf{m} \text { CeOx MRF }\end{array}$ & $\begin{array}{c}\text { Vendor 2 Etched - } \\
\text { Conditioned 1 } \mu \text { m } \\
\text { nano-diamond } \\
\text { MRF }\end{array}$ \\
\hline $\mathbf{4}$ & 0.13 & 0.00 & 0.01 & 0.00 & 0.00 & 0.00 \\
\hline $\mathbf{6}$ & 0.24 & 0.00 & 0.01 & 0.00 & 0.00 & 0.00 \\
\hline $\mathbf{8}$ & 0.29 & 0.38 & 0.31 & 0.00 & 0.00 & 0.02 \\
\hline $\mathbf{1 0}$ & 0.46 & 0.48 & 0.47 & 0.18 & 0.02 & 0.04 \\
\hline $\mathbf{1 2}$ & 10.00 & 1.34 & 1.43 & 0.50 & 0.02 & 0.27 \\
\hline $\mathbf{1 4}$ & 314.00 & 2.66 & 2.86 & 1.05 & 0.18 & 0.52 \\
\hline
\end{tabular}

This damage density is still about a factor of 2-3 larger than that observed on the best performing conventionally finished large aperture optic with and $3 \omega$ laser conditioning (Vendor 1 conditioned, baseline 2). Etching and laser conditioning appear to reduce the damage density to a point depending upon the initial quality of the optic, which is in this case is poor, but reach a floor where they can not bring about any more improvement. This is consistent with the observations noted on the other optic families tested.

Application of MRF final polishing to the Vendor 2 conventionally finished optics using either nano-diamond or CeOx MR fluid to remove $1 \mu \mathrm{m}$ of fused silica from the polished surfaces show improvements in damage resistance when combined with the $3 \omega$ post processing procedure. After etching of $1 \mu \mathrm{m}$ from the optic surfaces and application of $3 \omega$ laser conditioning, the Vendor 2 nano-diamond MRF polished optic shows about a factor of 600 improvement compared to the untreated part. The damage density is equivalent to the performance observed for the best performing conventionally finished large aperture optic with and $3 \omega$ laser conditioning (Vendor 1 conditioned, baseline 2). A factor of 1700 improvement is obtained using $\mathrm{CeOx}$ MRF polishing and the full advanced finishing treatment which yields superior performance 4 times better than that measured for the Vendor 2 conditioned optic. This trend is consistent to that noted in the Vendor 1 MRF finishing experiments. $\mathrm{CeOx}$ MR fluid appears to be more effective than nano-diamond MR fluid in removing the subsurface damage layer without leaving behind remnants which promote damage. A major conclusion drawn from the experiments on the Vendor 2 supplied optics is that significant improvements can be made on poorly performing conventionally finished optics by using etching and $3 \omega$ laser conditioning; however, when combined with

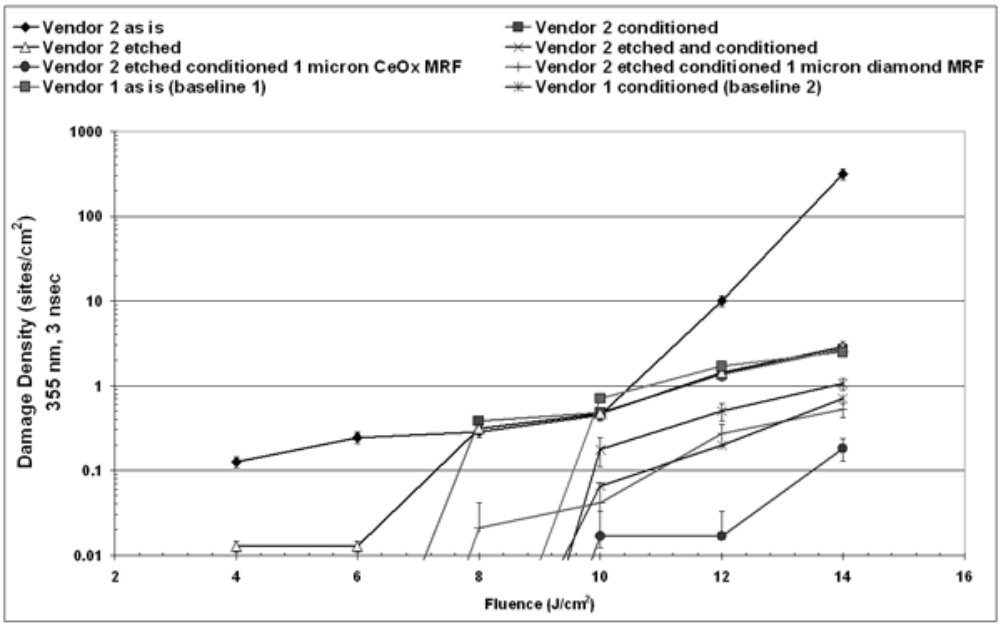

Figure 6: Damage density observed at $355 \mathrm{~nm}, 3 \mathrm{nsec}$, on $14.3-\mathrm{cm} \times$ $14.3-\mathrm{cm} \times 1.0-\mathrm{cm}$ fused silica optic cut from full size NIF high aspect ratio optic polished by Vendor 2. MRF final polishing, the optics can be made into superior performers. Like in the Vendor 1 experiments, the experiments on the Vendor 2 optics indicate that the quality of the optic prior to MRF final polishing may be important in determining the ultimate damage performance due to the thickness of the subsurface damage layer resulting from the conventional finishing process. The MRF removal may have to be optimized for the specific processes used for finishing before MRF final polishing to ensure that a sufficient amount of material is removed from the surfaces to get past the subsurface damage. 


\subsection{MRF Final Finishing and 3 $\omega$ Post Processing of LLNL Conventionally Finished Fused Silica Optics}

Additional CeOx lap polishing of subsections cut from the Vendor 2 supplied conventionally finished optics is intended to test the possibility of improving performance through careful removal of fused silica from the optical surfaces prior to MRF final polishing. The goal in these experiments is to remove material under small normal loads to remove or minimize the subsurface damage layer present from prior fabrication steps. A further assumption is that additional lapping of $25 \mu \mathrm{m}$ from the optical surfaces is sufficient to eliminate these effects. The results of large aperture damage testing on the subsections are presented in Table 5 and Figure 7.

Table 5: Damage density observed on $14.3-\mathrm{cm} X 14.3-\mathrm{cm} \times 1.0-\mathrm{cm}$ fused silica optic cut from full size NIF high aspect ratio optic polished by Vendor 2 and subsequently polished at LLNL using subsurface damage management. Reported damage density is in sites $/ \mathrm{cm}^{2}$ after illumination by 1 shot/site at $355 \mathrm{~nm}$ with no correction for beam shape. Fluences are scaled to equivalent values at 3-nsec.

\begin{tabular}{|c|c|c|c|}
\hline $\begin{array}{c}\text { Fluence } \\
\left(\mathbf{J} / \mathbf{c m}^{\mathbf{2}}\right)\end{array}$ & $\begin{array}{c}\text { LLNL CeOx Etched } \\
\text { and Conditioned }\end{array}$ & $\begin{array}{c}\text { LLNL CeOx Etched - } \\
\text { Conditioned 1 } \boldsymbol{\mu m ~ C e O x ~} \\
\text { MRF }\end{array}$ & $\begin{array}{c}\text { LLNL CeOx Etched - } \\
\text { Conditioned 1 } \boldsymbol{\mu m} \text { nano- } \\
\text { diamond MRF }\end{array}$ \\
\hline $\mathbf{4}$ & 0.00 & 0.00 & 0.00 \\
\hline $\mathbf{6}$ & 0.00 & 0.03 & 0.04 \\
\hline $\mathbf{8}$ & 0.00 & 0.03 & 0.06 \\
\hline $\mathbf{1 0}$ & 0.05 & 0.05 & 0.16 \\
\hline $\mathbf{1 2}$ & 0.23 & 0.11 & 0.29 \\
\hline $\mathbf{1 4}$ & 0.53 & 0.20 & 0.53 \\
\hline
\end{tabular}

Overall, the results of etching, $3 \omega$ laser conditioning, and combined $\mathrm{MRF} / 3 \omega$ post processing are similar to those obtained for the Vendor 2 supplied optics. Etching $1 \mu \mathrm{m}$ from the surfaces of the optic and applying $3 \omega$ laser conditioning yields damage performance equivalent to that observed on the best performing conventionally finished

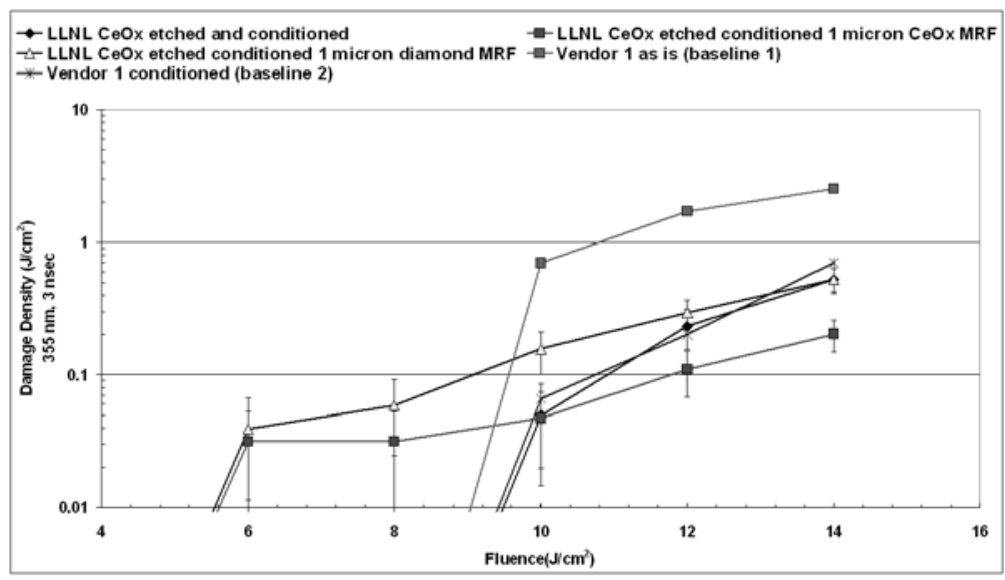

Figure 7: Damage density observed after illumination by 1 shot/site at $355 \mathrm{~nm}$ with no correction for beam shape. Fluences are scaled to equivalent values at 3-nsec. large aperture optic with $3 \omega$ laser conditioning (Vendor 1 conditioned, baseline 2). This performance is a factor of 2 better than the Vendor 1 etched and conditioned optic which suggests that the additional material removal from the lapping process was successful at reducing the subsurface damage layer thickness. Application of MRF final polishing to the LLNL CeOx conventionally finished optics using either nano-diamond or $\mathrm{CeOx}$ MR fluid to remove $1 \mu \mathrm{m}$ of fused silica from the polished surfaces show improvement in damage resistance when combined with the $3 \omega$ post processing procedure. A comparison of nano-diamond and $\mathrm{CeOx}$ MR fluid shows that the $\mathrm{CeOx}$ based fluid results in optics with superior UV damage resistance. For the $\mathrm{CeOx}$ MRF polished sample, the damage performance is about 3-4 times better than that observed on the Vendor 1 conditioned part. This is consistent with the trend observed on the other optic families tested from Vendor1 and Vendor 2. On the whole, these experiments suggest that additional lap polishing creates new damage or chases existing damage in the optics and that the combined MRF/3 $\omega$ post processing procedure is more effective and efficient at removing the deleterious effects of prior optical fabrication processes to bring about superior damage performance. 


\section{CONCLUSIONS}

The large area damage tests conducted on optics finished by a number of different vendors show that MRF, when combined with appropriate $3 \omega$ post-processing, significantly reduces the damage sensitivity for high fluence UV laser light. This is true regardless of the quality of the original conventional finishing. MRF can successfully remove subsurface damage and the contaminants contained therein leaving a high quality surface with little to no subsurface pits and cracks that could interact with the laser beam to induce damage. Even though MRF is successful at removing subsurface damage, the final MRF polish generates a new polishing layer containing MR fluid components at levels that are sufficient to promote damage. The MRF-induced polishing layer can be successfully removed via etching and laser conditioning to yield superior performance. This is in contrast to the subsurface layer generated by conventional polishing which contains debris and a large number of pits and cracks which lead to a high probability for retention of optically absorbing species that can initiate damage when irradiated at high fluence. The MRF finishing process shows promise when combined with etching and $3 \omega$ laser conditioning in decreasing the damage concentration to levels that can be managed by mitigation procedures currently being considered for use on high laser damage threshold optical flats as well as continuous phase plates. Application of either nano-diamond or $\mathrm{CeOx}$ MRF final polishing results in significant damage performance improvement, with the CeOx MRF process being superior. Additionally, nano-diamond MRF polished parts possess more numerous damage sites that are larger in size. The present experiments also show that the quality of the optic before MRF has some effect on the ultimate performance of the optic after application of the combined $\mathrm{MRF} / 3 \omega$ post-processing procedure. Ultimate and reliable performance depends on the amount of subsurface damage present which suggests that the MRF process needs to be optimized to the specific processes used for optical fabrication to ensure that a sufficient amount of material is removed. The combined MRF $3 \omega$ post-processing procedure is flexible. It can be used during initial optic fabrication to provide for superior damage performance or it can be used on existing lesser quality conventionally finished parts to improve performance beyond that attainable by using conventional techniques and post processing alone.

\section{ACKNOWLEDGEMENTS}

The authors would like to thank Andrea Flammini and Alene Clasen for their support in preparing this manuscript. This work was performed under the auspices of the U.S. Department of Energy at Lawrence Livermore National Laboratory, under contract No. W-7405-Eng-48.

\section{REFERENCES}

1. A.K. Burnham, L. Hackel, P. Wegner, T. Parham, L. Hrubesh, B. Penetrante, P. Whitman, S. Demos, J. Menapace, M. Runkel, M. Fluss, M. Feit, M. Key, T. Biesiada, "Improving 351-nm damage performance of large-aperture fused silica and DKDP optics", Laser Induced Damage in Optical Materials, this proceedings, Boulder (2001).

2. A. M. Rubenchik and M. D. Feit, "Initiation, growth, and mitigation of UV damage in fused silica", Laser Induced Damage in Optical Materials, this proceedings, Boulder (2001).

3. A. Salleo, R. Chinsio, F. Y. Genin, "Crack propagation in fused silica during UV and IR ns-laser illuminations", Laser Induced Damage in Optical Materials, SPIE Proc. 3578, 456-471 (1998).

4. J. Murray, "Overview of the National Ignition Facility", SPIE 3492 supplement, 1-10 (1998).

5. B. M. Van Wonterghem, J. R. Murray, J. H. Campbell, S.R. Speck, C. E. Barker, I. C. Smith, B.F. Browning, W.C. Behrendt, "Performance of a prototype for a large-aperture multi-pass Nd:glass laser for inertial confinement fusion", Applied Optics, 36, 4932-4952 (1997).

6. R. M. Brusasco, B. M. Penetrante, J. A. Butler, and L. W. Hrubesh, "Localized $\mathrm{CO}_{2}$ laser treatment for mitigation of $3 \omega$ damage growth in fused silica", Laser Induced Damage in Optical Materials, this proceedings, Boulder (2001).

7. B. M. Penetrante, R. M. Brusasco, J. A. Butler, S. M. Maricle, and J. E. Peterson, " $\mathrm{CO}_{2}$ laser polishing for reduction of $3 \omega$ damage initiation in fused silica", Laser Induced Damage in Optical Materials, this proceedings, Boulder (2001).

8. L. W. Hrubesh, M. A. Norton, W. A. Molander, E. E. Donohue, S. M. Maricle, B. M. Penetrante, R. M. Brusasco, W. Grundler, J. A. Butler, J. W. Carr, R. M. Hill, L. J. Summers, M. D. Feit, A. Rubenchik, M. H. Key, P. J. Wegner, A. K. Burnham, L. A. Hackel, and M. R. Kozlowski, "Methods for mitigating surface damage growth in NIF final optics", Laser Induced Damage in Optical Materials, this proceedings, Boulder (2001). 
9. B. M. Penetrante, J. E. Peterson, S. M. Maricle, and R. M. Brusasco, "UV laser conditioning for reduction of $3 \omega$ damage initiation in fused silica", Laser Induced Damage in Optical Materials, this proceedings, Boulder (2001).

10. Z. Gu, P. Liang, and W. Zhang, "Influence of glass surface layers on laser-induced damage threshold", Laser Induced Damage in Optical Materials, this proceedings, Boulder (2001).

11. P. Bouchut, P. Garrec, J. Newport, P. Gacoin, F. Bonnemason, S. Kaladgew, "Technological processing of silica as seen through laser induced damage tests", Laser Induced Damage in Optical Materials, this proceedings, Boulder (2001).

12. M. J. Fluss, J. Plitzko, M. Wall, "Initiation identification in 355-nm optics", Laser Induced Damage in Optical Materials, this proceedings, Boulder (2001).

13. T. Hoshino, Y. Kurata, Y. Kurata, Y. Terasaki, and K. Susa, "Mechanism of polishing of $\mathrm{SiO}_{2}$ films by $\mathrm{CeO}_{2}$ particles", Journal of Non-Crystalline Solids, 283, 129-136 (2001).

14. D. W. Camp, M. R. Kozlowski, L. M. Sheehan, M. Nichols, M. Dovik, R. Raether, I. Thomas, "Subsurface damage and polishing compound affect at the 355-nm laser damage threshold of fused silica surfaces", Laser Induced Damage in Optical Materials, SPIE Proc. 3244, 356-364 (1997).

15. D. Golini, S. Jacobs, W. Kordonski, and P. Dumas, "Precision optics fabrication using magnetorheological finishing", Advanced Materials for Optics and Precision Structures, CR67, 251-274 (1997).

16. A. B. Shorey, S. D. Jacobs, W. I. Kordonski, and R. F. Gans, "Experiments and observations regarding mechanisms of glass removal in magnetorheological finishing", Applied Optics, 40, No. 1, 20-33 (2001).

17. W. Kordonski, D. Golini, P. Dumas, and S. Jacobs, "Magnetorheological suspension-based finishing technology", SPIE, 3326, 527-535 (1998).

18. S. D. Jacobs, D. Golini, Y. Hsu, B. E. Puchebner, D. Strafford, W. I. Kordonski, I. V. Prokhorov, E. Fess, D. Pietrowski, and V. W. Kordonski, "Magnetorheological finishing: a deterministic process for optics manufacturing", SPIE, 2576, 372-382 (1995).

19. S. D. Jacobs. F. Yang, E. M. Fess, J. B. Feingold, B. E. Gillman, W. I. Kordonski, H. Edwards, and D. Golini, "Magnetorheological finishing of IR materials", SPIE, 3134, 258-269 (1997).

20. S. R. Arrasmith, I. A. Kozhinova, L. L. Greg, A. B. Shorey, H. J. Romanofsky, S. D. Jacobs, D. Golini, W. I. Kordonski, S. Hogan, and P. Dumas, "Details of the polishing spot in magnetorheological finishing", SPIE, 3782, 92-100 (1999).

21. D. Golini, W. I. Kordonski, P. Dumas, and S. Hogan, "Magnetorheological finishing (MRF) in commercial precision optics manufacturing", SPIE, 3782, 80-91 (1999).

22. G. A. C. M. Spierings, "Review: Wet chemical etching of silicate glasses in hydrofluoric acid based solutions", Journal of Materials Science, 28, 6261-6273 (1993).

23. S. Frieders, "Precision cleaning of bare fused silica optics", LLNL Draft Processing Procedure, (2001).

24. S. Schwartz, M. D. Feit, M. R. Kozlowski, and R. P. Mouser, "Current $3 \omega$ large optic test procedures and data analysis for quality assurance of National Ignition Facility optics", Laser Induced Damage in Optical Materials, SPIE Proc., 3578, 314-321 (1998). 


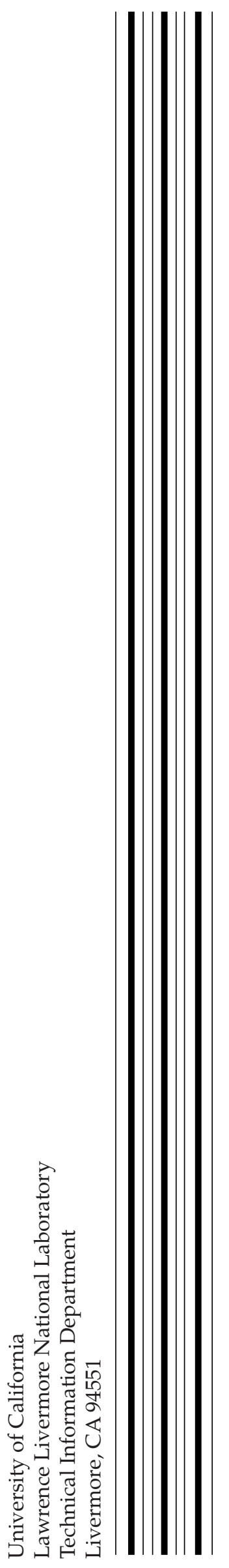

